Гуманитарные ведомости ТГПУ им. Л. Н. Толстого № 2 (34), октябрь 2020 г.

Ю. В. Назарова

Тульский государственный педагогический университет

им. Л. Н.Толстого

\title{
ЭТИКА ИСКУССТВЕННОГО ИНТЕЛЛЕКТА В СОВРЕМЕННОЙ РОССИИ: АКТУАЛЬНЫЕ ПРОБЛЕМЫ И ТЕНДЕНЦИИ РАЗВИТИЯ
}

В статье рассматривается содержание этики искусственного интеллекта, выявляются наиболее актуальные на сегодняшний день этические проблемы применения искусственного интеллекта. Показано, что процесс внедрения технологий искусственного интеллекта, приобретший в нашей стране правовую базу, остро нуждается в этической рефлексии. В этой связи в статье проводится анализ смыслового содержания термина «искусственный интеллект»; определяется фрилософская область исследования ИИ; обозначаются локус, этос, приемлемость ИИ, а также этико-нормативное основание ИИ. В заключении статьи выявляются перспективы развития этики ИИ. За основу анализа в статье взяты новейшие исследования по этике искусственного интеллекта, а также по этическим и социальным последствиям его применения, проводившиеся как в отечественной науке, так и зарубежом.

Ключевые слова: искусственный интеллект; этика искусственного интеллекта, цифровая этика; этос искусственного интеллекта.

Yu. V. Nazarova

Tula State Lev Tolstoy Pedagogical University,

(Russia, Tula)

\section{ETHICS OF ARTIFICIAL INTELLIGENCE IN MODERN RUSSIA: CURRENT CHALLENGES AND DEVELOPMENT TRENDS}

The article examines the content of the ethics of artificial intelligence. It is shown that the process of introducing artificial intelligence technologies, which has acquired a legal basis in our country, is in dire need of ethical reflection. In this regard, on the basis of new philosophical studies related to the problems of artificial intelligence, the article analyzes the semantic content of the term "artificial intelligence" (AI); the philosophical area of research of $\mathrm{Al}$ is determined; the locus, ethos, acceptability of $\mathrm{Al}$, and the ethical-normative basis of $\mathrm{Al}$ are indicated. In the conclusion of the article, the prospects for the development of Al ethics are identified. The analysis is based on the latest research on the ethics of artificial intelligence, as well as on the ethical and social consequences of its use, conducted both in domestic science and abroad.

Keywords: artificial intelligence; ethics of artificial intelligence, digital ethics; ethos of artificial intelligence.

DOI 10.22405/2304-4772-2020-1-2-14-23

Актуальность вопроса об этической стороне внедрения в повседневную жизнь технологий искусственного интеллекта обусловлена тем, что в настоящее время в России начался эксперимент по внедрению искусственного интеллекта в медицину, бизнес, транспортные и логистические системы, согласно Федеральному закону от 24.04 .2020 № 123 «О проведении эксперимента по установлению специального регулирования в целях создания необходимых условий для разработки и внедрения технологий искусственного 
Гуманитарные ведомости ТГПУ им. Л. Н. Толстого № 2 (34), октябрь 2020 г.

интеллекта в субъекте РФ - городе федерального значения Москве и внесении изменений в ст.6 и 10 Федерального закона «О персональных данных». Данный эксперимент, несомненно, является уверенным шагом в новое цифровое общество, что предполагает ряд масштабных последствий в социальной, культурной, экономической и политической сферах. Однако уже на первоначальном этапе эксперимента встает много вопросов, преимущественно, этического характера, которые, на данный момент, кажутся более актуальными, чем предполагаемая научная и экономическая польза, ответы на которые и составляют содержание этики искусственного интеллекта.

Целью статьи является исследование содержания этики искусственного интеллекта (далее - ИИ).

В этой связи, предполагается проанализировать следующие проблемы:

- уточнить содержание термина «Искусственный интеллект»;

-обозначить философскую область исследования ИИ;

-обозначить природу искусственного интеллекта, которая определяет содержание этики ИИ: локус, этос, приемлемость ИИ;

-определить этико-нормативные основания ИИ;

-определить перспективы развития этики ИИ.

Искусственный интеллект - смысловое содержание термина

Искусственный интеллект - термин, выбранный автором статьи на основании правовых норм РФ. Так, согласно Указу Президента Российской Федерации от 10.10.2019 г. № 490 «О развитии искусственного интеллекта в Российской Федерации», ИИ определяется как «комплекс технологических решений, позволяющий имитировать когнитивные функции человека (включая самообучение и поиск решений без заранее заданного алгоритма) и получать при выполнении конкретных задач результаты, сопоставимыле, как минимум, $c$ результатами интеллектуальной деятельности человека. Комплекс технологических решений включает в себя информационнокоммуникационную инфраструктуру, программное обеспечение (в том числе в котором используются методы машинного обучения), процессы и сервисы по обработке данных и поиску решений» [8] (Курсив автора - Ю. Н.).

Уже это первоначальное определение ИИ позволяет обозначить ряд вопросов этического характера, связанных с проблемой ответственности. Например, вопроса о том, кто будет нести ответственность за последствия результатов, которые «сопоставимые, как минимум, с результатами интеллектуальной деятельности человека»?

Существует также термин «интеллектуальные технические системы (ИТС), что, на наш взгляд, более точно отражает техническую сущность ИИ, однако, поскольку в исследовании идет речь о проблеме ИИ в целом, а не о ситуационных проблемах этики ИИ, связанных со специфическими техническими особенностями систем, мы остановимся на термине ИИ. В том же документе ИТС определяется как «технологии, основанные на использовании искусственного интеллекта, включая компьютерное зрение, обработку естественного языка, распознавание и синтез речи, 
Гуманитарные ведомости ТГПУ им. Л. Н. Толстого № 2 (34), октябрь 2020 г.

интеллектуальную поддержку принятия решений и перспективные методы искусственного интеллекта» [8].

Р. Г. Апресян, уточняет терминологическую разницу между ИТС и ИИ, так как это необходимо для определения содержания этики ИИ, определяя ИТС как «технические системы, способные самостоятельно (без оперативного контроля со стороны) решать поставленные задачи в условиях меняющихся внешних параметров функционирования» [2, с. 169]. В этом смысле, по словам исследователя, ИИ в этическом смысле более содержателен, чем ИТС, поскольку включает в себя проблему «...не только самого по себе функционирования ИТС и того, как решаются поставленные перед ними и возникающие в ходе их функционирования задачи, но и деятельности по разработке такого рода систем, их подготовке к работе и их обслуживанию, а также социальных, гуманитарных, экологических и возможных других эффектов их использования. Этическим проблемам такого рода, хотя они в настоящее время более насущны, не уделяется достаточного внимания» [2, c.169-170].

Анализ мнений отечественных представителей философской науки показал, что этика ИИ конкретизируется в нескольких направлениях, которые структурированы автором статьи на основании исследований, представленных на XI международной конференции «Теоретическая и прикладная этика: традиции и перспективы. К грядущему цифровому обществу. Опыт этического прогнозирования» (100 лет со дня рождения Д.Белла - 1919-2019) (21-23 ноября 2019 г., Санкт-Петербург)».

Философская область исследования этики ИИ относится как к философской, так и к прикладной этике. С точки зрения философской этики этика ИИ предстает как этика ответственности (И. Я. Авдеева). Этика будущего в свете техногенных достижений должна расширить свои границы в сторону коллективной ответственности человечества, причем ответственности не только за настоящее и прошлое, но и за будущее: «в моральной оценке последствий собственных поступков мы уже не можем руководствоваться только ответственностью перед современниками и руководствоваться деонтологией уважения к абстрактному нравственному закону, но должны принимать во внимание ответственность перед будущим человечеством прежде всех остальных принципов этики, устанавливая ее в качестве базы не только морального, но и политического, экологического, экономического мышления» [1, с. 168]. На наш взгляд, в контексте ответственности особенный смысл приобретает этическое прогнозирование, главная цель которого предупреждение этических последствий развития науки и техники. Поэтому цифровая этика, и этика ИИ, несомненно, имеет прогностический характер.

С точки зрения прикладной этики этика ИИ расширяет свое содержание. Р. Г. Апресян подчеркивает, что этические проблемы ИИ необходимо рассматривать не только с точки зрения философской этики и философии ценностей, но, с точки зрения прикладной этики, что, во многом меняет философский подход к рассмотрению этих проблем: «Этика как моральная 
Гуманитарные ведомости ТГПУ им. Л. Н. Толстого № 2 (34), октябрь 2020 г.

философия - сориентирована на обобщенное и абстрактное понятие морали: оно не всегда отражает внутреннюю неоднородность морали и соотнесено с той или иной практикой. Поэтому необходима прикладная этика. Этика ИТС сориентирована на практику, связанную с функционированием ИТС. В ее задачу входит описание этой практики, включенных в нее агентов, реципиентов, связанных с ней третьих лиц, чтобы понимать, какие интересы затрагиваются этой практикой, какие конфликты возникают или могут возникнуть. Названные выше ценности и соответствующие им императивы должны быть спроецированы на эту практику и конкретизированы (не формализованы) по отношению к тому функционалу, которым наделяются ИТС и, что очень важно, к тем конфликтам, которые возможны в ходе осуществления этого функционала» [2, с. 169]. Таким образом, этические проблемы искусственного интеллекта нужно решать при помощи прикладной этики, конкретнее, цифровой этики, соединяющей в себе как этические, так и правовые, и социологические и специфические технологические инструменты.

В Лаборатории Цифровой Этики при Оксфордском университете и Оксфордском интернет-институте (Digital Ethics Lab), наряду с актуальными исследованиями в разных отраслях цифровой этики, проводятся исследования этических и социальных последствий искусственного интеллекта. На сайте Лаборатории отмечены следующие этически и социально значимые проблемы ИИ: 1) рост безработицы, вследствие распространения ИИ; 2) распространение ложной информации; 3) несправедливые или необъективные решения, основанные на заранее заложенных в ИИ алгоритмах; 3) непредсказуемая социальная реакция на ИИ финансовых рынков или других систем. Тем не менее, исследователи этики ИИ отмечают, что нельзя накладывать на ИИ чрезмерные ограничения, поскольку это приведет к упущению таких возможностей ИИ, как медицинская диагностика, снижение преступности или научные исследования (Перевод мой - Ю. Н.) [9]. Этика ИИ определяется Digital Ethics Lab как часть цифровой этики, наряду с такими проблемами цифровой этики, исследуемыми Лабораторией, как 1) этика и экономика смерти в век информации; 2) этические проблемы, связанные с использованием новых технологий в финансовых услугах - или «FinTech» (этика Финтеха); 3) этика больших биомедецинских данных; 4) этика и политика киберконфликтов; 5) этика порнографии ИИ; 6) этика алгоритмов и так далее [9].

Природа ИИ, которая определяет содержание этики ИИ: локус, этос, приемлемость, нормативная сторона ИИ.

На сайте Лаборатории Цифровой этики отмечается, что этика ИИ, как часть цифровой этики, связана с идеалами информационного общества: «Мы помогаем построить лучшее информационное общество: открытое, плюралистическое, толерантное, равноправное и справедливое. Наша цель выявить преимущества и расширить положительные возможности цифровых инноваций, а также избежать или уменьшить их риски и недостатки» [9] (Перевод мой - Ю. Н.). Таким образом, на содержание этики ИИ влияют 
Гуманитарные ведомости ТГПУ им. Л. Н. Толстого № 2 (34), октябрь 2020 г.

ценности информационного общества, которые являются критериями для оценок нравственной стороны ИИ.

Для определения содержания этики ИИ важно конкретизировать его отличительные черты (И. В. Маркова, Д. А. Давыдов). Авторы перечисляют такие особенности ИИ, как «понимание языка, обучение и способность мыслить и, что немаловажно, принимать решения готовность действовать. ИИ - комплекс родственных технологий и процессов, развивающихся качественно и стремительно, например: обработка текста на естественном языке, машинное обучение, экспертные системы, виртуальные агенты (чатботы и виртуальные помощники), системы рекомендаций» [4, с. 171-173]. (Курсив мой - Ю. Н.)

Этика ИИ, как часть цифровой этики, находится на границах с другими видами как прикладной, так и профессиональной этики, что показывают сферы применения ИИ, среди которых И. В. Маркова и Д. А. Давыдов выделяют такие сферы, как «применение ИИ в обороноспособности и военном деле: искусственный интеллект в ВПК, кибервойны, боевые роботы. Применение ИИ на транспорте: автопилот (беспилотный автомобиль), автоиндустрия на пороге революции: эра беспилотного вождения. Искусственный интеллект позволит изменить операционную модель логистики с реактивной на прогнозируемую, работающую на опережение... Также ИИ применяют для анализа поведения граждан, в медицине, образовании, банковском секторе и прочих сферах жизнедеятельности человека» [4, с. 171-173].

С философской точки зрения сфера применения ИИ так или иначе определяет этос ИИ (А. Н. Положенцев): «...изучением этоса безличной субъектности, принципов, которыми она уже руководствуется в своей организации нашего жизненного пространства, выводить правила взаимодействия с ней и воздействия на нее, ограничения ее, регулировать степень ее проникновения в личность и ее жизнь, исследовать, как она видоизменяет наш собственный габитус и создает из нас конгруэнтную собственным целям личность» [7, с. 175-177]. Таким образом, определение этоса ИИ могло бы стать методологическим механизмом реконструкции этики ИИ, четкого определения ее сферы, ее границ.

Также для определения содержания этики ИИ важным вопросом остается вопрос о приемлемости и адекватности применения моральных норм вообще в цүифровой среде, например, вопрос «о правомерности применимости понятия морали к описанию поведения искусственных агентов - роботов или аниматов» (В. Э. Карпов) [3, с. 170-171] или вопрос о цифровом доверии человека, основанный на этических принципах, используемых в цифровой среде (М. Д. Мартынова): «Проблема цифрового доверия связана с моральнопсихологической готовностью человека организовывать свою жизнедеятельность в новой для него цифровой среде и опираться в этой среде на привычные этические принципы» [5, с. 173-174].

Этико-правовые основания ИИ 
М. Таддео и Л. Флориди отмечают, что распространенность ИИ, а также привычка к ИИ в повседневной жизни создают еще одну фундаментальную этическую проблему: влияние ИИ на принятие человеком решений, что опять подводит к вопросу об этике ответственности, являющимся основным в этике ИИ. Несмотря на то, что в разных областях ИИ, как отмечают исследователи, приоритетными становятся разные этические принципы (например, доверие и открытость имеют решающее значение при внедрении ИИ-решений в домах, школах или больницах, тогда как равенство, справедливость и защита творческих способностей и прав сотрудников важны для интеграции ИИ на рабочем месте), основным этическим принципом применения ИИ остается принцип ответственности [10; с. 751-752]. Вопрос о правом статусе ИИ и его правовом регулировании определяет содержание этики ИИ; в то же самое время, этическое прогнозирование проблем с ИИ может определять правовой статус ИИ и правовое регулирование. Так, в этико-нормативном смысле, ИИ связан с проблемой ответственности за технологические результаты и принятие ИИ решений. В этом случае, как с правовой, так и с моральной точек зрения, ответственность ложится на разработчиков конкретной программы ИИ (Д. В. Огородов): «В рамках правовой системы РФ заметная часть вопросов этики ИИ имеет прямое юридическое значение. Так, в проекте «Машина морали» была смоделирована моральная дилемма траектории беспилотного автомобиля при неожиданном появлении препятствия: продолжать движение прямо, жертвуя пассажирами ради спасения пешеходов; либо свернуть в сторону и пожертвовать пешеходами ради спасения пассажиров. Автопроизводитель Mercedes-Benz в 2016 году намеревался решать эту дилемму в пользу пассажиров, позже дезавуировав свое заявление под шквалом критики» $[6,174-$ 175].

\section{Bblводbl:}

Этика ИИ является частью цифровой этики - областью прикладной этики, рассматривающей моральные проблемы формирующегося цифрового общества, где ИИ является одной из таких проблем. Этические проблемы ИИ могут быть осмыслены при помощи синтеза подходов философской и прикладной этики.

Этика ИИ находится на границах с другими видами прикладной этики, которые могут расширяться и дополняться вместе с развитием технологий. На данный момент можно говорить о том, что этика ИИ связана с: инженерной этикой, военной этикой; этикой права; этикой образования; политической этикой; экономической этикой; биомедицинской этикой. Поэтому можно сделать вывод, что этика ИИ ситуативна по своей природе: в каждой сфере ИИ на границах с каждым из перечисленных видов этики действуют не одинаковые нравственные ценности и нормы.

Важным остается вопрос о приемлемости применения привычных моральных норм к ИИ, что ставит перед цифровым обществом ряд вопросов: кто должен нести ответственность за решения ИИ? Должен ли быть в поведении ИИ заложен некий моральный алгоритм, и, наконец, самый 
Гуманитарные ведомости ТГПУ им. Л. Н. Толстого № 2 (34), октябрь 2020 г.

основной вопрос - допустимо ли технологизировать мораль? Последний вопрос ставит эту проблему не только на этический, но и правовой уровень.

Должна ли технологизация этики ИИ быть заложена в праве?

В этой связи важный вопрос этики ИИ заключается в следующем: должна ли этика ИИ быть зафиксирована в праве и технологизирована в алгоритмах ИИ, или четкие этические требования должны применяться к разработчикам ИИ на стадии его разработки, либо нужно совместить оба варианта?

Такое разнообразие вопросов и размытость сфер применения ИИ заставляют согласиться с идеей исследования «этоса безличной субъектности», с целью реконструкции этики ИИ, но эта идея поможет исследовать этику ИИ в теоретическом, умозрительном смысле, в то время как поворот в сторону цифровой этики позволит конкретизировать проблемы ИИ, подвергнув их всестороннему анализу.

\section{Лumepamypa}

1. Авдеева И. А. Ответственность в эпоху техногенной цивилизации / XI международная конференция «Теоретическая и прикладная этика: Традиции и перспективы - 2019. К грядущему цифровому обществу. Опыт этического прогнозирования (100 лет со дня рождения Д. Белла - 1919-2019)». Санктпетербургский Государственный Университет, 21-23 ноября 2019 г. Материалы конференции / Отв. ред. В. Ю. Перов. СПб.: ООО «Сборка», 2019. С.168-169.

2. Апресян Р. Г. Этика и дискуссии об искусственном интеллекте / XI международная конференция «Теоретическая и прикладная этика: Традиции и перспективы - 2019. К грядущему цифровому обществу. Опыт этического прогнозирования (100 лет со дня рождения Д. Белла - 1919-2019)». Санктпетербургский Государственный Университет, 21-23 ноября 2019 г. Материалы конференции / Отв. ред. В. Ю. Перов. СПб.: ООО «Сборка», 2019. С. 169-170.

3. Карпов В. Э. Моральные отношениям между искусственным агентами / XI международная конференция «Теоретическая и прикладная этика: Традиции и перспективы - 2019. К грядущему цифровому обществу. Опыт этического прогнозирования (100 лет со дня рождения Д. Белла - 1919-2019)». Санкт-петербургский Государственный Университет, 21-23 ноября 2019 г. Материалы конференции / Отв.ред. В. Ю. Перов. СПб.: ООО «Сборка», 2019. С. 170-171.

4. Маркова И. В., Давыдов Д. А. ИИ в современном цифровом обществе: проблема этической рефлексии / XI международная конференция «Теоретическая и прикладная этика: Традиции и перспективы - 2019. К грядущему цифровому обществу. Опыт этического прогнозирования (100 лет со дня рождения Д. Белла - 1919-2019)». Санкт-петербургский Государственный Университет, 21-23 ноября 2019 г. Материалы конференции / Отв. ред. В. Ю. Перов. СПб.: ООО «Сборка», 2019. С. 171-172. 
Гуманитарные ведомости ТГПУ им. Л. Н. Толстого № 2 (34), октябрь 2020 г.

5. Мартынова М. Д. Дилеммы «цифрового доверия» и их влияние на нравственное развитие личности в контексте становления «цифрового образования» / XI международная конференция «Теоретическая и прикладная этика: Традиции и перспективы - 2019. К грядущему цифровому обществу. Опыт этического прогнозирования (100 лет со дня рождения Д. Белла - 19192019)». Санкт-петербургский Государственный Университет, 21-23 ноября 2019 г. Материалы конференции / Отв. ред. В. Ю. Перов. СПб.: ООО «Сборка», 2019. C. 173-174.

6. Огородов Д. В. Этика искусственного интеллекта и правовая система России: решенные вопросы и направления развития / XI международная конференция «Теоретическая и прикладная этика: Традиции и перспективы - 2019. К грядущему цифровому обществу. Опыт этического прогнозирования (100 лет со дня рождения Д. Белла - 1919-2019)». Санктпетербургский Государственный Университет, 21-23 ноября 2019 г. Материалы конференции / Отв. ред. В. Ю. Перов. СПб.: ООО «Сборка», 2019. С. 174-175

7. Положенцев А. М. Безличный разум как цель (к дискуссии об этике искусственного интеллекта) / ХІ международная конференция «Теоретическая и прикладная этика: Традиции и перспективы - 2019. К грядущему цифровому обществу. Опыт этического прогнозирования (100 лет со дня рождения Д.Белла - 1919-2019)». Санкт-петербургский Государственный Университет, 21-23 ноября 2019 г. Материалы конференции / Отв. ред. В. Ю. Перов. СПб.: ООО «Сборка», 2019. С. 175-177.

8. Указ Президента Российской Федерации от 10.10 .2019 г. № 490 «О развитии искусственного интеллекта в Российской Федерации». URL: http://www.kremlin.ru/acts/bank/44731 (дата обращения: 22.07.2020).

9. Лаборатория цифровой этики при Оксфордском университете официальный сайт: Digital Ethics Lab. URL: https://digitalethicslab.oii.ox.ac.uk. (дата обращения: 22.07.2020).

10. Taddeo M.; Floridi L. How AI can be a force for good / Science. Vol. 361(6404). P. 751-752 / Digital Ethics Lab. URL: https://digitalethicslab.oii.ox.ac.uk. (дата обращения: 22.07.2020).

\section{References}

1. Avdeeva I. A. Otvetstvennost' v epokhu tekhnogennoy tsivilizatsii [Responsibility in the era of technological civilization]. XI mezhdunarodnaya konferentsiya «Teoreticheskaya i prikladnaya etika: Traditsii i perspektivy - 2019. K gryadushchemu tsifrovomu obshchestvu. Opyt eticheskogo prognozirovaniya (100 let so dnya rozhdeniya D. Bella - 1919-2019)». Sankt-peterburgskiy Gosudarstvennyy Universitet, 21-23 noyabrya 2019 g. Materialy konferentsii. Editor-in-chief V. Yu. Perov. St. Petersburg: OOO «Sborka» Publ., 2019. Pp.168-169. [In Russian]

2. Apresyan R. G. Etika i diskussii ob iskusstvennom intellekte [Ethics and discussions about artificial intelligence]. XI mezhdunarodnaya konferentsiya «Teoreticheskaya i prikladnaya etika: Traditsii i perspektivy - 2019. K 
Гуманитарные ведомости ТГПУ им. Л. Н. Толстого № 2 (34), октябрь 2020 г.

gryadushchemu tsifrovomu obshchestvu. Opyt eticheskogo prognozirovaniya (100 let so dnya rozhdeniya D. Bella - 1919-2019)». Sankt-peterburgskiy Gosudarstvennyy Universitet, 21-23 noyabrya 2019 g. Materialy konferentsii. Editor-in-chief V. Yu. Perov. St. Petersburg: OOO «Sborka» Publ., 2019. Pp. 169-170. [In Russian]

3. Karpov V. E. Moral'nyye otnosheniyam mezhdu iskusstvennym agentami [The moral relationship between artificial agents]. XI mezhdunarodnaya konferentsiya «Teoreticheskaya i prikladnaya etika: Traditsii i perspektivy - 2019. K gryadushchemu tsifrovomu obshchestvu. Opyt eticheskogo prognozirovaniya (100 let so dnya rozhdeniya D. Bella - 1919-2019)». Sankt-peterburgskiy Gosudarstvennyy Universitet, 21-23 noyabrya 2019 g. Materialy konferentsii. Editor-in-chief V. Yu. Perov. St. Petersburg: OOO «Sborka» Publ., 2019. Pp. 170-171. [In Russian]

4. Markova I. V., Davydov D. A. II v sovremennom tsifrovom obshchestve: problema eticheskoy refleksii [AI in the modern digital society: the problem of ethical reflection]. XI mezhdunarodnaya konferentsiya «Teoreticheskaya i prikladnaya etika: Traditsii i perspektivy - 2019. K gryadushchemu tsifrovomu obshchestvu. Opyt eticheskogo prognozirovaniya (100 let so dnya rozhdeniya D. Bella - 1919-2019)». Sankt-peterburgskiy Gosudarstvennyy Universitet, 21-23 noyabrya 2019 g. Materialy konferentsii. Editor-in-chief V. Yu. Perov. St. Petersburg: OOO «Sborka» Publ., 2019. Pp. 171-172. [In Russian]

5. Martynova M. D. Dilemmy «tsifrovogo doveriya» i ikh vliyaniye na nravstvennoye razvitiye lichnosti v kontekste stanovleniya «tsifrovogo obrazovaniya» ["Digital trust" dilemmas and their impact on the moral development of the individual in the context of "digital education"]. XI mezhdunarodnaya konferentsiya «Teoreticheskaya i prikladnaya etika: Traditsii i perspektivy - 2019. K gryadushchemu tsifrovomu obshchestvu. Opyt eticheskogo prognozirovaniya (100 let so dnya rozhdeniya D. Bella - 1919-2019)». Sankt-peterburgskiy Gosudarstvennyy Universitet, 21-23 noyabrya 2019 g. Materialy konferentsii. Editor-in-chief V. Yu. Perov. St. Petersburg: OOO «Sborka» Publ., 2019. Pp. 173-174. [In Russian]

6. Ogorodov D. V. Etika iskusstvennogo intellekta i pravovaya sistema Rossii: reshennyye voprosy i napravleniya razvitiya [Ethics of artificial intelligence and the legal system of russia: resolved issues and directions for development]. XI mezhdunarodnaya konferentsiya «Teoreticheskaya i prikladnaya etika: Traditsii i perspektivy - 2019. K gryadushchemu tsifrovomu obshchestvu. Opyt eticheskogo prognozirovaniya (100 let so dnya rozhdeniya D.Bella - 1919-2019)». Sanktpeterburgskiy Gosudarstvennyy Universitet, 21-23 noyabrya 2019 g. Materialy konferentsii. Editor-in-chief V. Yu. Perov. St. Petersburg: OOO «Sborka» Publ., 2019. Pp. 174-175. [In Russian]

7. Polozhentsev A. M. Bezlichnyy razum kak tsel' (k diskussii ob etike iskusstvennogo intellekta) [Impersonal mind as a goal (to the discussion on the ethics of artificial intelligENCE)]. XI mezhdunarodnaya konferentsiya «Teoreticheskaya i prikladnaya etika: Traditsii i perspektivy - 2019. K gryadushchemu tsifrovomu obshchestvu. Opyt eticheskogo prognozirovaniya (100 let so dnya rozhdeniya D.Bella - 1919-2019)». Sankt-peterburgskiy Gosudarstvennyy Universitet, 21-23 
Гуманитарные ведомости ТГПУ им. Л. Н. Толстого № 2 (34), октябрь 2020 г.

noyabrya 2019 g. Materialy konferentsii. Editor-in-chief V. Yu. Perov. St. Petersburg: OOO «Sborka» Publ., 2019. Pp. 175-177. [In Russian]

8. Ukaz Prezidenta Rossiyskoy Federatsii ot 10.10 .2019 g. № $490 \ll \mathrm{O}$ razvitii iskusstvennogo intellekta v Rossiyskoy Federatsii» [Decree of the president of the Russian Federation №. 490 dated 10.10.2019 "On the development of artificial intelligence in the Russian Federation"]. Available at: http://www.kremlin.ru/acts/bank/44731 (accessed: 13.07.2020). [In Russian]

9. Digital Ethics Lab. Available at: https://digitalethicslab.oii.ox.ac.uk (accessed: 22.07.2020).

10. Taddeo M.; Floridi L. How AI can be a force for good / Science. Vol. 361(6404). P. 751-752 / Digital Ethics Lab. Available at: https://digitalethicslab.oii.ox.ac.uk (accessed: 22.07.2020).

11. Taddeo M.; Floridi L. How AI can be a force for good / Science. Vol. 361(6404). P. 751-752 / Digital Ethics Lab. Available: https://digitalethicslab.oii.ox.ac.uk (accessed: 22.07.2020).

Статья поступила в редакииюю 12.08 .2020

Статья допущена к публикаџии 15.10.2020

The article was received by the editorial staff 12.08 .2020

The article is approved for publication 15.10.2020 